Published in Earth Surface Processes and Landforms, v. 32, pp. 1116-1127 (2007) @ John Wiley \& Sons, Ltd. DOI: 10.1002/esp.1464

\title{
Development of algebra algorithms for automated generation of grain- size distribution maps
}

Short title: algebra algorithms for automated generation of grain-size maps

\author{
Alessandro Sarretta ${ }^{a}$, Mauro Masiol ${ }^{b}$, Emanuela Molinaroli ${ }^{\mathbf{b}^{*}}$ \\ ${ }^{a}$ CNR - Istituto di Scienze Marine, Riva VII Martiri 1364/A, 30122 Venezia, Italy \\ b Università Ca’ Foscari, Dipartimento di Scienze Ambientali, Dorsoduro 2137, 30123 \\ Venezia, Italy \\ *Corresponding author. Tel.: +39-041-2348583; fax +39-041-2348510. E-mail address: \\ molinaro@unive.it
}

\begin{abstract}
The grain-size distribution of sediments is a fundamental characteristic in understanding the earth's surface environments and an essential tool in classifying sedimentary environments. Grain-size data provide important information on the energy and dynamics of depositional environments and aid our understanding of sediment transport. Ternary diagrams (TD) are useful and conventional tools to classify sediments on the basis of relative grain-size (i.e., gravel, sand, mud or sand, silt, clay). The development of spatial modelling in a Geographical Information System (GIS) can assist in treating, computing and displaying sedimentological data, such as grain-sizes.
\end{abstract}


In this work, four map algebra (MA) algorithms are written in a GIS environment to automatically produce maps depicting the spatial distribution of sediment texture classes based on the most frequently used grain-size TD: the Shepard classification, Flemming classification for sand/silt/clay components, and Folk et al. classification Blair and McPherson classification for sand/gravel/mud components. The proposed method allows rapid assessments by producing map distributions of the parameters most widely used in sedimentology.

Keywords: ternary diagrams, grain-size distribution, GIS, map algebra.

\section{Introduction}

Grain-size distributions have been extensively used by sedimentologists to understand the source, transport and history of sediments (Folk and Ward, 1957; Friedman, 1979; McCave and Syvitski, 1991; Pye and Blott, 2004), and to classify sedimentary environments (Folk and Ward, 1957; Reed et al., 1975; Taira and Scholle, 1979; McLaren and Bowles, 1985; Singer et al., 1988; Vandenberghe et al., 1997).

Over the last twenty-five years, there has been renewed interest in the significance of grain-size data in environmental studies, relating fine-grained samples to micropollutants in several marine and transitional settings (Albertazzi et al., 1987; Moore et al., 1989; Hieke Merlin et al., 1992; Hathaway et al., 1994).

A number of studies have focused on comparisons of techniques used for grain-size determination (Stein, 1985; Syvitski, 1991; Konert and Vandenberghe, 1997; Pye, 1994; Molinaroli et al., 2000). McCave and Syvitski (1991) described the principal techniques 
for particle size analysis and made recommendations as to the preferred method for specific purposes.

Study of sediment properties and distribution is essential for understanding several fundamental earth surface processes such as river and sea dynamics, coastal morphology, fluvial, eolian and glacial sedimentary transport, pollution, plant and animal distribution, etc. Grain size is a basic physical parameter of clastic rocks, which provides information on the energy and dynamic conditions of sedimentary environments.

Geographical Information Systems (GIS) are frequently used to map the spatial distribution of environmental variables. The spatial trend of a single variable is usually mapped by interpolating spot variables. Environmental data are mainly derived from separate samplings, which then need spatial distribution models in order to describe the continuous space which is the field of interest in this type of research.

Algorithms capable of performing spatial analysis on gridded data can simplify the interpretation of sedimentary data such as grain size. Map algebra (MA), a high-level computational language used for spatial cartographic analysis of raster data, has recently been implemented in GIS (Tomlin, 1990). MA is a set of mathematical expressions applied to spatial data. It uses arithmetic, relational, Boolean, and logical mathematical operators to solve complex spatial problems.

In this work, we developed four MA algorithms to classify and map sediment texture classes based on the most frequently used grain-size ternary diagrams (TD): Shepard (1954) and Flemming (2000) for sand/silt/clay components, Folk et al. (1970) and Blair and McPherson (1999) for sand/gravel/mud ones. Two case studies are presented for sand, silt and clay (Lagoon of Venice, Italy) and gravel, sand and mud (silt+clay) 
(Block Island Sound, U.S.A.). The procedure can be used in sedimentary studies to: (a) classify sediment grain-size characteristics; (b) build maps of sediment distribution; (c) view trends in sediment distribution; and (d) locate changes in grain-size distributions over time.

The approach described could also be used for mapping any tri-variate data based on proportions of a whole.

\section{Grain-size analysis and ternary classifications}

Nomenclature describing size distributions is important to geologists because grain size is the most basic attribute of sediments (Poppe et al., 2003a). Descriptive classifications and nomenclatures identifying size distributions can distinguish between various sediment types on the basis of rational criteria, can reduce ambiguity, and have the advantage of ease communication and discussion of observations and analytical results (Flemming, 2000). The primary division comprises four size fractions - gravel, sand, silt and clay, the sediments being classified according to the ratios of the various proportions of the fractions. The first size classification was presented by Wentworth (1922) who defined the boundaries of various fractions.

Krumbein (1933) introduced the use of TD to display sediment textures graphically. The three end-members of the diagram show the relative proportions of the components. Although several classifications have been adopted to describe the approximate relationship between size fractions, most sedimentologists either use the system introduced by Shepard (1954) (Fig. 1a) or by Folk (1968) (Fig. 1b). The two diagrams have 10 subdivisions and 7 names in common for textural classes of unequal proportions. Given the detail in many recent studies of fine-grained sediments, both schemes are rather approximate, in that most classes have widely spaced boundaries 
encompassing sediment mixtures covering fairly large textural ranges (Flemming, 2000).

The Shepard system (Fig. 1a) does not accept sediments with significant amounts of gravel. To overcome this Folk et al. (1970) proposed a TD for the distinction of specific gravel/sand/mud ratios (Fig. 1c), then Blair and McPherson (1999) (Fig. 1d) modified the Folk classification for better coverage of gravelly sediment.

Several other authors have proposed alternative triangular diagrams, e.g., Reineck and Siefert (1980), Pejrup (1988) and Flemming (2000), which emphasise sand, silt and clay ratios. Pejrup (1988) modified Folk's TD (Fig. 1b) on the basis of hydrodynamic considerations, improving the classification from a genetic viewpoint. The silt/clay axis was divided in two parts $(50 \%)$ and additional partition lines were added to define silt/clay ratios of 2:1 and 1:2, resulting in four hydrodynamic groups between silt and clay end-members.

Starting from the considerations of Reineck and Siefert (1980) and Pejrup (1988), Flemming (2000) suggested a new grain-size classification for gravel-free muddy sediments, permitting applications at various levels of complexity depending on requirements and available textural information. Using the same basic terminology, Flemming (2000) identified the advantage of this scheme in improved spatial resolution of textural provinces. His system is composed of twenty-five classes and separates classes for sand and mud end-members better than previous methods. The names (e.g., very silty sand) can be used to describe a depositional environment on the basis of sediment texture (e.g., a very silty sand facies). In addition, the letter-number code can be used to label distribution of sediment facies in maps (Fig. 1e and Tab. 1). 
In our study, we used TD based on Shepard's sand/silt/clay ratios representing the “classical - approximate" approach, and Flemming's new and improved classification, which has the advantage of taking hydrodynamic factors into account. To study coarsegrained sediments, we examined the diagram of Folk et al. based on gravel/sand/mud ratios and Blair and McPherson (1999), who modified the Folk et al. textural classification to produce descriptions of gravelly sediment rivalling those of finer sediment in objectivity and detail.

Recent works propose Excel spreadsheet (Tri-Plot by Graham and Midgley, 2000) or software (SEDCLASS by Poppe, 2003b) for easier creation of TD.

However, many scientific questions and policy issues related to sediments require distribution maps, so it is often crucial to represent spatial grain-size data on them. Maps are convenient and widely-used tools to represent observations, inferences and conclusions regarding the complex spatial relationships inherent in three- or fourdimensional data (Lewis and McConchie, 1994). Such maps are usually compiled by a "manual" system, classifying each sample by grain-size parameters and then drawing a map. The development of computerised data analysis and the GIS method implemented by MA led to an automated system of producing maps.

\section{The map algebra algorithms}

The main aim of this study was automatic spatial representation of sedimentological classifications defined according to TDs, starting from grain-size point data. For this purpose, sampling points of sediments had to be geo-referenced, saved in shape format (.shp) and represented as point layers in ESRI ArcGIS 8.3 software. 
The first step was to transform the vectorial point-source layer into a raster format, by a spatial interpolation procedure. A raster-type file is formed of a regular grid of elements (pixels), each of which represents a portion of a territory and contains a number representing the mean value of a certain variable for that portion of the territory.

Spatial interpolation uses a set of techniques which, given a space in which the values taken on by a parameter are measured at various points, can determine values in points where the parameter in question was not measured but is based on other known values. Discrete, fragmented information thus becomes a continuous representation of that variable.

The percentages of the three sediment end-members were thus interpolated by the Spatial Analyst extension within ArcGIS 8.3 software. Various types of interpolation models can be used, ranging from a simple deterministic (Inverse Distance Weighting, IDW) to the sophisticated geostatistical types (e.g., kriging). In this study, we used the IDW model, which estimates the values of variables at unknown points as weighted means derived from measurements taken at nearby points, giving greater weight to the nearest points (Longley et al., 2001).

This choice was dictated by the fact that our main aim was to develop a method for processing grain-size data, and not in-depth analysis of spatial relations between the data and the accuracy of the interpolation. The method may be adapted and perhaps be expanded to specific frameworks by choosing different techniques of data interpolation in order to be evaluated according to the type of variable studied, sampling method, etc. Starting from the three end-members referring to the sampling points, this method yielded three raster files, which represent the spatial distribution of the three grain-size 
intervals. Their information was then integrated in a single raster file by means of an MA algorithm.

By MA, we mean the use of logical and mathematical operators applied to grids which show territorial data as a series of geometric constraints. One essential condition for the use of MA is that all the data must be of the same dimension, in terms of both domain (the ground area covered by the raster grid) and resolution. Inside ArcGIS, the "Raster Calculator", which is a calculator attributing a value which is a function of the values of the corresponding elements of the input layers to each element in the output layers.

In this case, the input layers are the raster files of the three end-members. A new raster in which the data are reclassified into a chosen number of classes, which correspond to the same number of types of sediment, are created as output using several arithmetical $(+, /)$ and relational $(>,>=,<,<=,=)$ operators. Figure 2 shows the concept of the algebraic operation applied to the informational layers typical of MA which yield informative layers as a result of these operations. When one raster is overlaid on another, as if they were a "mathematical sandwich", simple arithmetic can be applied to the most sophisticated algorithms.

The commands and operations among the files are written in Visual Basic for Applications (VBA), which offers the same instruments as Visual Basic within the context of the existing application.

In table 2 the algorithm is written to map sediment distribution according to Shepard's (1954) classification.

The names of the input files appear inside square brackets (in this case, sand, silt, clay). Receiving the order "con", the algorithm compares the three input files pixel by pixel and, for each output pixel, assigns certain values (whole numbers: $0,1,2, \ldots, 10$ ) if 
certain conditions are verified (e.g., >=75). As it proceeds, the algorithm verifies whether the first condition has been accepted; if not, it passes to the second and so on, until it finds the true condition for the pixel in question. This procedure is repeated for all the pixels in the output file. If no condition is verified, the algorithm assigns a value of 0 .

After the algorithm has been executed, the output file is composed of classified pixels (whole numbers) according to the subdivision shown in the ternary sedimentological diagram. In this way, spatial representation can achieved automatically. Starting from sampled point data, the variables of interest appear according to a classification based on the contemporaneous use of three variables.

The algorithms for the classification of Folk et al. (1970), Blair and McPherson (1999) and Flemming's system are presented in tables 3, 4 and 5, respectively.

\section{Application of the algorithms: two examples}

The MA algorithms written to represent sedimentological classifications defined according to TDs have been tested on two cases. The first is the Lagoon of Venice, Italy, a very complex ecosystem not very well known from the sedimentological viewpoint and in which sediments are fine, the sandy fraction is confined to fine sand and there are no gravel sediments. The second is the Block Island Sound, U.S.A., a very well studied area in which sand, gravel and mud are present.

\section{The Lagoon of Venice, Italy}

The Lagoon of Venice is located along the north-west coast of the Adriatic Sea $\left(45^{\circ} \mathrm{N} ; 12^{\circ} \mathrm{E}\right)$ and is the largest lagoon in the Mediterranean. It is a complex ecosystem, 
affected by natural factors and thousands of years of human influence. The Lagoon covers an area of $550 \mathrm{~km}^{2}$ of which $5 \%$ is deeper than $5 \mathrm{~m}$ and $75 \%$ shallower than 2 $\mathrm{m}$; the average depth is $1.2 \mathrm{~m}$. The Lagoon is connected to the Adriatic by three inlets (Lido, Malamocco, Chioggia) permitting water and sediment exchange driven by the tidal cycle. At the present time, the area suffers from a series of problems due to the presence of the city of Venice, heavy metal and organic pollution from the industrial zone of Porto Marghera, shipping (both commercial-industrial and private vessels), intense and in many cases illegal clam harvesting, and mechanical dredging of channels. The samples processed in this study are part of a database from the Water Authority (MAV-CVN, 1999). Bottom sediment samples $(\sim 15 \mathrm{~cm})$ from the Lagoon of Venice were collected at 96 sites during fieldwork in 1997-1998 organised by the Consorzio Venezia Nuova (C.V.N.) and sponsored by the Magistrato alle Acque (Water Authority).

Figure 3 shows the sediment samples as classified by the TD of Shepard (Fig. 3a) and Flemming (Fig. 3b). In Shepard's system, samples are distributed in six textural classes, whereas in Flemming's they occupy nine, so the latter is preferable as it is more precise in describing the texture of a particular sediment sample. The condition of the Lagoon's sediments is more similar to the higher-energy environments described in Flemming (2000), so the sedimentary processes acting in the Lagoon of Venice are more comparable to those of a bay than a lagoon.

We applied algorithms related to both classification systems. Figure 4 and 5 show the spatial distribution of sediments in the Lagoon according to the two systems. As clearly evident, the classification of Flemming (2000) produces a distinctly superior spatial differentiation. 
The maps presented in figures 4 and 5 are the result of the IDW interpolation used as input for the algorithms. Table 6 shows the number of samples grouped for each lithological type by the classification systems (actual value) and by the IDW (by definition the same number of samples for each lithological type) and kriging interpolations. In Shepard and Flemming systems the kriging misclassified $44 \%$ and $63 \%$ of samples respectively, introducing some evidence of artefacts. Application of the Flemming classification scheme to interpolated data - which is subject to considerable uncertainty - may result in a lack of precision in the resulting map. Where the precision of the interpolation is uncertain, the use of a classification scheme with fewer subclasses would thus be more appropriate.

Given that the maps can be used to determine spatial and temporal variations in sediment texture (of possible use for environmental management decisions), it is important that they are reliable indicators of the true pattern of sediment texture. The choice of an appropriate interpolation method is therefore critical.

\section{Block Island Sound, U.S.A.}

Block Island Sound $\left(41^{\circ} 9.8^{\prime} \mathrm{N} ; 71^{\circ} 36.6^{\prime} \mathrm{W}\right)$ is a strait along the open Atlantic coast of North America, approximately 10 miles wide, separating Block Island from the coast of Rhode Island. Geographically, it is both the eastward extension of Long Island Sound and the westward extension of Rhode Island Sound. The samples processed in this study form part of the "Coastal and Marine Geology Program", U.S. Geological Survey (http://pubs.usgs.gov/of/2003/of03-001/data/seddata/savard66/savard66.zip). The U.S. Geological Survey Open-File Report 03-001 is from Poppe et al. (2003a). A total of 84 surface sediment samples were processed. The data presented in this source show 
sediment distributions and describe the sedimentary environments and processes along this portion of the continental shelf. Figure 6 shows the sediment samples as classified by Folk et al. (Fig. 6a) and by Blair and McPherson (1999) (Fig. 6b). The samples fall into ten textural classes in the Folk et al. system, whereas in Blair and McPherson they occupy eleven, with only one sample falling into the extra class. The algorithm relative to Folk's classification was applied, and only this is shown because of the similarity with the Blair and McPherson system. Figure 7 shows the spatial distribution of sediments in the Block Island Sound according to this classification. The Block Island Sound sediments are prevalently slightly gravelly sand, slightly gravelly muddy sand and gravelly sand, so the Blair and McPherson system, which covers the coarser range of sedimentary particles including various grades of pebbles, cobbles, and boulders in the gravel fraction, and various grades of blocks, slabs, monoliths, and megaliths in the megagravel fraction is not very useful.

\section{Conclusions}

1. The MA algorithms developed here are able to produce maps automatically, depicting the spatial distribution of sediment textural classes based on the most frequently used grain-size TD: those of Shepard (1954) and Flemming (2000) for sand/silt/clay components; Folk et al. (1970) and Blair and McPherson for sand/gravel/mud components.

2. The proposed MA algorithms for sediment classification are useful and simple to apply: (a) to classify sediments on the basis of grain-size; (b) to compile maps of 
sediment distributions; (c) to study trends in sediment distribution; (d) to identify changes in grain-size distributions over time.

3. The algorithm is extremely flexible in terms of the input of end-members, and may therefore be applied to several fields in Earth Sciences, such as geochemistry, sedimentology or paleontology. 


\section{References}

Albertazzi S, Hieke Merlin O, Menegazzo Vitturi L, Molinaroli E, Tassi Pelati L. 1987. Distribution and behaviour of 137Cs in nearshore sediments of the northern Adriatic Sea and at the Adige River estuary, northern Italy. Appl. Geochem. 2: 357-366.

Blair TC, McPherson JG. 1999. Grain-size and textural classification of coarse sedimentary particles. Journal of Sedimentary Research 69: 6-19.99

Flemming BW. 2000. A revised textural classification of gravel-free muddy sediments on the basis of ternary diagrams. Continental Shelf Research 20: 1125-1137.

Folk RL. 1968. Petrology of Sedimentary Rocks. Hemphill's Bookstore: Austin.

Folk RL, Ward WC. 1957. Brazos River bar: a study in the significance of grain-size parameters. J. Sediment. Petrol. 27: 3-26.

Folk RL, Andrews PB, Lewis DW. 1970. Detrital sedimentary rock classification and nomenclature for use in New Zealand. Journal of Geology and Geophysics 13: 937968.

Friedman GM. 1979. Differences in size distributions of populations of particles among sands of various origins. Sedimentology 26: 3-32.

Graham DJ, Midgley NG. 2000. Graphical Representation of Particle Shape Using Triangular Diagrams: An Excel Spreadsheet Method. Earth Surf. Process. Landforms 25: 1473-1477.

Hathaway JC, Buchholz ten Brink MR, Manheim FT, Bothner MH. 1994. Contaminated sediments in Boston Harbour and Massachusetts Bay: spatial and temporal trends. Eos 75 (3): 144. 
Hieke Merlin O, Menegazzo Vitturi L, Molinaroli E, Morani A, Tassi Pelati L. 1992. Chernobyl fallout and radionuclide activity depth-profiles in sediments at the River Adige estuary (Northern Adriatic Sea, Italy). Terra Nova 4: 434-442.

Konert M, Vandenberghe J. 1997. Comparison of laser grain size analysis with pipette and sieve analysis: a solution for the underestimation of the clay fraction. Sedimentology 44: 523-535.

Krumbein WC. 1933. Textural and lithological variations in glacial till. Journal of Geology 41: 382-408.

Lewis DW, McConchie D. 1994. Practical Sedimentology. Chapman \& Hall: New York. Longley PA, Goodchild MF, Maguire DJ, Rhind DW. 2001. Geographic Information Systems and Science. Wiley Publisher.

MAV-CVN, 1999. Mappatura dell'inquinamento dei fondali lagunari. Studi ed indagini, relazione finale luglio 1999. Consorzio Venezia Nuova.

McCave IN, Syvitski JPM. 1991. Principles and methods of Geological Particle Size Analysis. In: Principles, Methods, and Application of Particle Size Analysis, Syvitski JPM (ed.). Cambridge University Press: Cambridge; 3-21.

McLaren P, Bowles D. 1985. The effects of sediment transport on grain size distributions. J. Sediment. Petrol. 55: 457-470.

Molinaroli E, De Falco G, Rabitti S, Portaro R. 2000. Stream-scanning laser system, electric sensing counter and settling grain size analysis: a comparison using reference materials and marine sediments. Sedimentary Geology 130 (3-4): 269-281.

Moore JN, Brook EJ, Johns C. 1989. Grain size partitioning of metals in contaminated coarse-grained river floodplain sediments: Clark Fork River, Montana, U.S.A. Environ. Geol. Water Sci. 14 (2): 107-115. 
Pejrup M. 1988. The triangular diagram used for classification of estuarine sediments: a new approach. In: Tide-Influenced Sedimentary Environments and Facies. de Boer PL, van Gelder A, Nio SD (eds.). Reidel: Dordrecht; 289-300.

Poppe LJ, Paskevich VF, Williams SJ, Hastings ME, Kelly JT, Belknap DF, Ward LG, FitzGerald DM, Larsen PF. 2003a. Surficial Sediment Data from the Gulf of Maine, Georges Bank, and Vicinity: A GIS Compilation. U.S. Geological Survey Open-File Report 03-001: http://pubs.usgs.gov/of/2003/of03-001.

Poppe LJ, Eliason AH, Hastings ME. 2003b. A Visual Basic program to classify sediments based on gravel-sand-silt-clay ratios. Computers \& Geosciences, 29: 805-809.

Pye K. 1994. Sediment transport and depositional processes. Blackwell Scientific Publications: Cambridge, MA.

Pye K, Blott SJ. 2004. Particle size analysis of sediments, soils and related particulate materials for forensic purposes using laser granulometry. Forensic Science International 144: 19-27.

Reed WE, LeFever R, Moir GJ. 1975. Depositional environment interpretation from settling velocity (psi) distribution. Geol. Soc. Am. Bull. 86: 1321-1328.

Reineck HE, Siefert W. 1980. Faktoren der Schlickbildung im Sahlenburger Watt und Neuwerker Watt. Die Krüste 35: 26-51.

Shepard FK. 1954. Nomenclature based on sand-silt-clay ratios. Journal of Sedimentary Research 24: 151-158.

Singer JK, Anderson JB, Ledbetter MT, McCave IN, Jones KPN, Wright R. 1988. An assessment of analytical techniques for the size analysis of fine-grained sediments. $J$. Sediment. Petrol. 58 (3): 534-543. 
Syvitski JPM. 1991. Principles, Methods, and Application of Particle Size Analysis. Cambridge University Press: Cambridge.

Stein R. 1985. Rapid grain-size analyses of clay and silt fractions by SediGraph 5000D: comparison with Coulter Counter and Atterberg methods. J. Sediment. Petrol. 55: $590-593$.

Taira A, Scholle PA. 1979. Discrimination of depositional environments using settling tube data. J. Sediment. Petrol. 49: 787-800.

Tomlin CD. 1990. Geographic information systems and cartographic modelling. Prentice Hall Englewood Cliffs: New Jersey.

Vandenberghe J, Zhisheng A, Nugteren G, Huayu L, Van Huissteden K. 1997. New absolute time scale for the Quaternary climate in the Chinese loess region by grainsize analysis. Geology 25 (1): 35-38.

Wentworth CK. 1922. A scale of grade and class terms for clastic sediments. Journal of Geology 30: 377-392. 


\section{TABLE CAPTIONS}

Table 1. Codes and descriptive terminology for 25 textural classes based on sand/silt/clay ratios as defined in Fig. 1e (table 2 from Flemming, 2000).

\begin{tabular}{ll|cl}
\hline Code & Textural class & Code & Textural class \\
\hline S & Sand & D-I & Extremely silty slightly sandy mud \\
A-I & Slightly silty sand & D-II & Very silty slightly sandy mud \\
A-II & Slightly clayey sand & D-III & Silty slightly sandy mud \\
& & D-IV & Clayey slightly sandy mud \\
B-I & Very silty sand & D-V & Very clayey slightly sandy mud \\
B-II & Silty sand & D-VI & Extremley clayey slightly sandy mud \\
B-III & Clayey sand & & \\
B-IV & Very clayey sand & E-I & Silt \\
& & E-II & Slightly clayey silt \\
C-I & Extremely silty sandy mud & E-III & Clayey silt \\
C-II & Very silty sandy mud & E-IV & Silty clay \\
C-III & Silty sandy mud & E-V & Slightly silty clay \\
C-IV & Clayey sandy mud & E-VI & Clay \\
C-V & Very clayey sandy mud & & \\
C-VI & Extremely clayey sandy mud & & \\
\hline
\end{tabular}

Table 2. The algorithm written to map sediment distribution according to Shepard's (1954) classification.

\begin{tabular}{|c|}
\hline$[$ silt $]>=75,4$, \\
\hline [clay] $>=75,7$, \\
\hline$[$ clay $]<20 \&[$ sand $]<75 \&[$ sand $]>=[$ silt $] \&[$ silt $]>=$ [clay $], 2$, \\
\hline$[$ clay $]<20 \&[$ silt $]<75 \&[$ silt $]>=[$ sand $] \&[$ clay $]<[$ sand $], 3$ \\
\hline$[$ sand $]<20 \&[$ silt $]<75 \&[$ silt] $>=[$ clay] $\&$ [clay] $>$ [sand], 5, \\
\hline$[$ sand] $<20 \&[$ clay $]<75 \&$ [clay] $>$ [silt] $\&[$ silt $]>$ [sand], 6, \\
\hline$[$ silt $]<20 \&$ [clay] $<75 \&$ [clay] $>[$ sand] $\&[$ sand $]>[$ silt], 8, \\
\hline$[$ silt $]<20 \&[$ sand $]<75 \&[$ sand $]>$ [clay] \& [clay] $>$ [silt], 9, \\
\hline
\end{tabular}


Table 3. The algorithm written to map sediment distribution according to Folk et al. (1970) classification.

\begin{tabular}{|c|}
\hline on (Igravel] $>=$ \\
\hline [gravel] $<80 \&$ [gravel] $>=30 \&[$ sand] $/[$ mud] $>=9,2$, \\
\hline [gravel] $\langle 80 \&$ [gravel] $\rangle=30 \&[$ sand] $/[$ mud] $\langle 9 \&[$ sand] $/[$ mud] $\rangle=1,3$, \\
\hline$[$ gravel] $<80 \&$ [gravel] $>=30 \&[$ sand $] /[$ mud] $<1,4$, \\
\hline [gravel] $\langle 30 \&$ [gravel] $\rangle=5 \&[$ sand] $/[\mathrm{mud}]>=9,5$, \\
\hline [gravel] $<30 \&$ [gravel] $>=5 \&[$ sand $] /[\mathrm{mud}]<9 \&[$ sand $] /[\mathrm{mud}]>=1,6$, \\
\hline$[$ gravel] $\langle 30 \&$ [gravel] $>=5 \&[$ sand $] /[$ mud $]<1,7$, \\
\hline [gravel] $\langle 5 \&$ [gravel] $\rangle=0.01 \&[$ sand $] /[\mathrm{mud}]\rangle=9,8$, \\
\hline [gravel] $\langle 5 \&$ [gravel] $\rangle=0.01 \&[$ sand] $/[$ mud] $]<9 \&[$ sand] $/[$ mud] $>=1,9$, \\
\hline$[$ gravel] $\langle 5 \&$ [gravel] $\rangle=0.01 \&[$ sand] $/[\mathrm{mud}]\langle 1 \&[\mathrm{sand}] /[\mathrm{mud}]\rangle=0.111,10$, \\
\hline [gravel] $<5 \&$ [gravel] $>=0.01 \&[$ sand] $/[\mathrm{mud}]<0.111,11$, \\
\hline [gravel] $\langle 0.01 \&[$ sand] $/[\mathrm{mud}]\rangle=9,12$, \\
\hline [gravel] $\langle 0.01 \&[\mathrm{sand}] /[\mathrm{mud}]<9 \&[\mathrm{sand}] /[\mathrm{mud}]\rangle=1,13$, \\
\hline [gravel] $<0.01 \&$ [sand] $/[\mathrm{mud}]<1 \&[$ sand] $/[\mathrm{mud}]>=0.111,14$, \\
\hline
\end{tabular}

Table 4. The algorithm written to map sediment distribution according to Blair and McPherson (1999) classification.

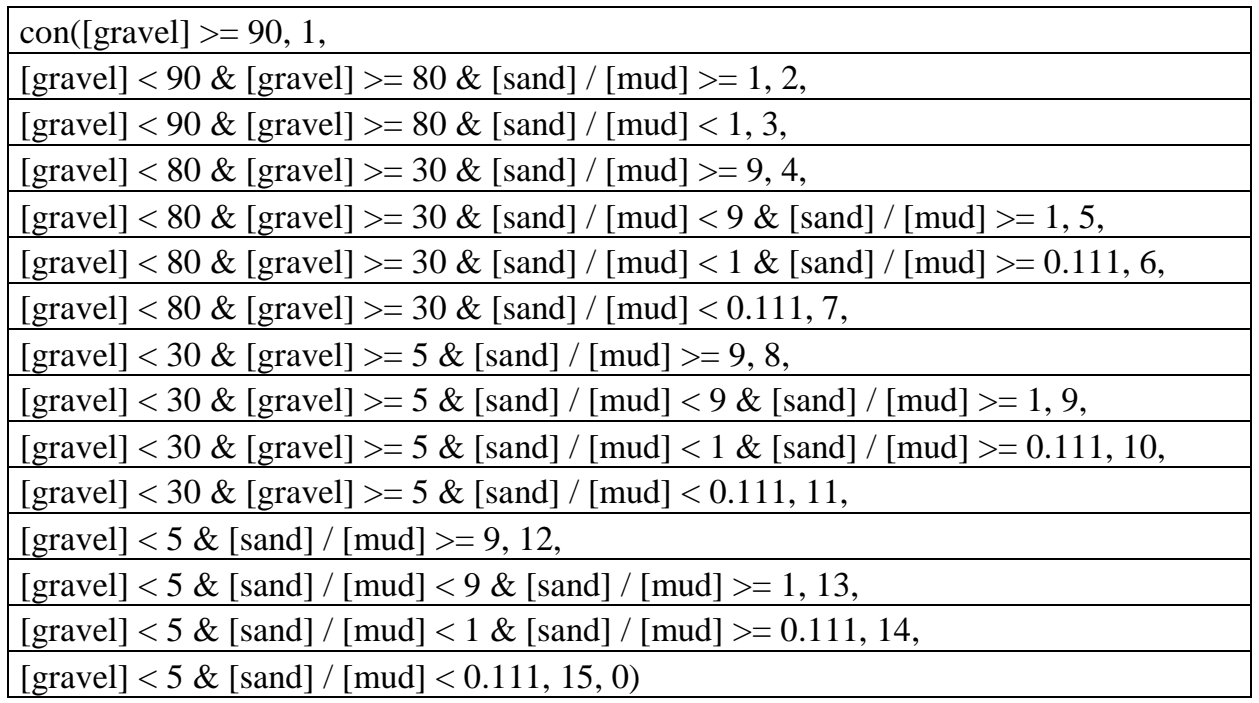


Table 5. The algorithm written to map sediment distribution according to Flemming (2000) classification.

\begin{tabular}{|c|}
\hline $\operatorname{con}([$ sand $]>=$ \\
\hline$[$ sand $]\langle 95 \&[$ sand $]\rangle=75 \&[$ clay $] /[$ silt $]\rangle=1,2$, \\
\hline$[$ sand $]<95 \&$ [sand] $>=75 \&$ [clay] $/[$ silt $]<1,3$, \\
\hline$[$ sand] $\langle 75 \&$ [sand] $\rangle=50 \&$ [clay] $/[$ silt] $\rangle=3,4$, \\
\hline$[$ sand] $<75 \&$ [sand] $>=50 \&$ [clay] $/$ [silt] $<3 \&$ [clay] $/$ [silt] $>=1,5$, \\
\hline$[$ sand $]\langle 75 \&[$ sand $]\rangle=50 \&[$ clay $] /[$ silt $]\langle 1 \&[$ clay $] /[$ silt $]\rangle=0.333,6$, \\
\hline$[$ sand] $<75 \&[$ sand] $>=50 \&$ [clay] $/[$ silt $]<0.333,7$, \\
\hline$[$ sand] $\langle 50 \&$ [sand] $\rangle=25 \&$ [clay] $/[$ silt] $\rangle=9,8$, \\
\hline [sand] $<50 \&$ [sand] $>=25 \&$ [clay] $/$ [silt] $<9 \&$ [clay] $/$ [silt] $>=3,9$, \\
\hline$[$ sand $]<50 \&[$ sand $]\rangle=25 \&[$ clay] $/[$ silt $]<3 \&[$ clay] $/[$ silt $]\rangle=1,10$ \\
\hline$[$ sand] $\langle 50 \&$ [sand] $\rangle=25 \&[$ clay] $/[$ silt $]\langle 1 \&$ [clay] $/[$ silt] $\rangle=0.333,11$, \\
\hline$[$ sand] $\langle 50 \&$ [sand] $>=25 \&$ [clay] $/[$ silt] $<0.333 \&$ [clay] $/[$ silt] $\rangle=0.111,12$, \\
\hline$[$ sand] $<50 \&$ [sand] $>=25 \&$ [clay] $/[$ silt $]<0.111,13$, \\
\hline [sand] $\langle 25 \&$ [sand] $\rangle=5 \&$ [clay] $/[$ silt] $\rangle=9,14$, \\
\hline$[$ sand] $\langle 25 \&$ [sand] $>=5 \&$ [clay] $/$ [silt] $<9 \&$ [clay] $/$ [silt] $\rangle=3,15$, \\
\hline$[$ sand] $<<25 \&$ [sand] $>=5 \&$ [clay] $/$ [silt] $<3 \&$ [clay] $/[$ silt] $\rangle=1,16$, \\
\hline$[$ sand] $\langle 25 \&$ [sand] $>=5 \&$ [clay] $/[$ silt $]<1 \&$ [clay] $/[$ silt] $\rangle=0.333,17$, \\
\hline$[$ sand] $\langle 25 \&$ [sand] $>=5 \&$ [clay] $/[$ silt $]<0.333 \&$ [clay] $/[$ silt] $>=0.111,18$, \\
\hline [sand] $<25 \&$ [sand] $>=5 \&$ [clay] $/[$ silt $]<0.111,19$, \\
\hline$[$ sand] $<5 \&$ [clay] $/[$ silt $]>=9,20$ \\
\hline [sand] $<5 \&$ [clay] $/$ [silt] $<9 \&$ [clay] $/$ [silt] $>=3,21$, \\
\hline$[$ sand] $<5 \&$ [clay] $/$ [silt] $<3 \&$ [clay] $/$ [silt] $>=1,22$, \\
\hline$[$ sand $]<5 \&$ [clay] $/[$ silt $]<1 \&$ [clay] $/[$ silt $]>=0.333,23$, \\
\hline$[$ sand] $<5 \&$ [clay] $/[$ silt $]<0.333 \&$ [clay] $/[$ silt $]>=0.111,24$, \\
\hline$[$ sand $]<5 \&$ [clay] $/[$ silt $]<0.111,25,0)$ \\
\hline
\end{tabular}


Table 6. Number of samples classified in the lithological type from Shepard classification and mapping the IDW and kriging interpolations.

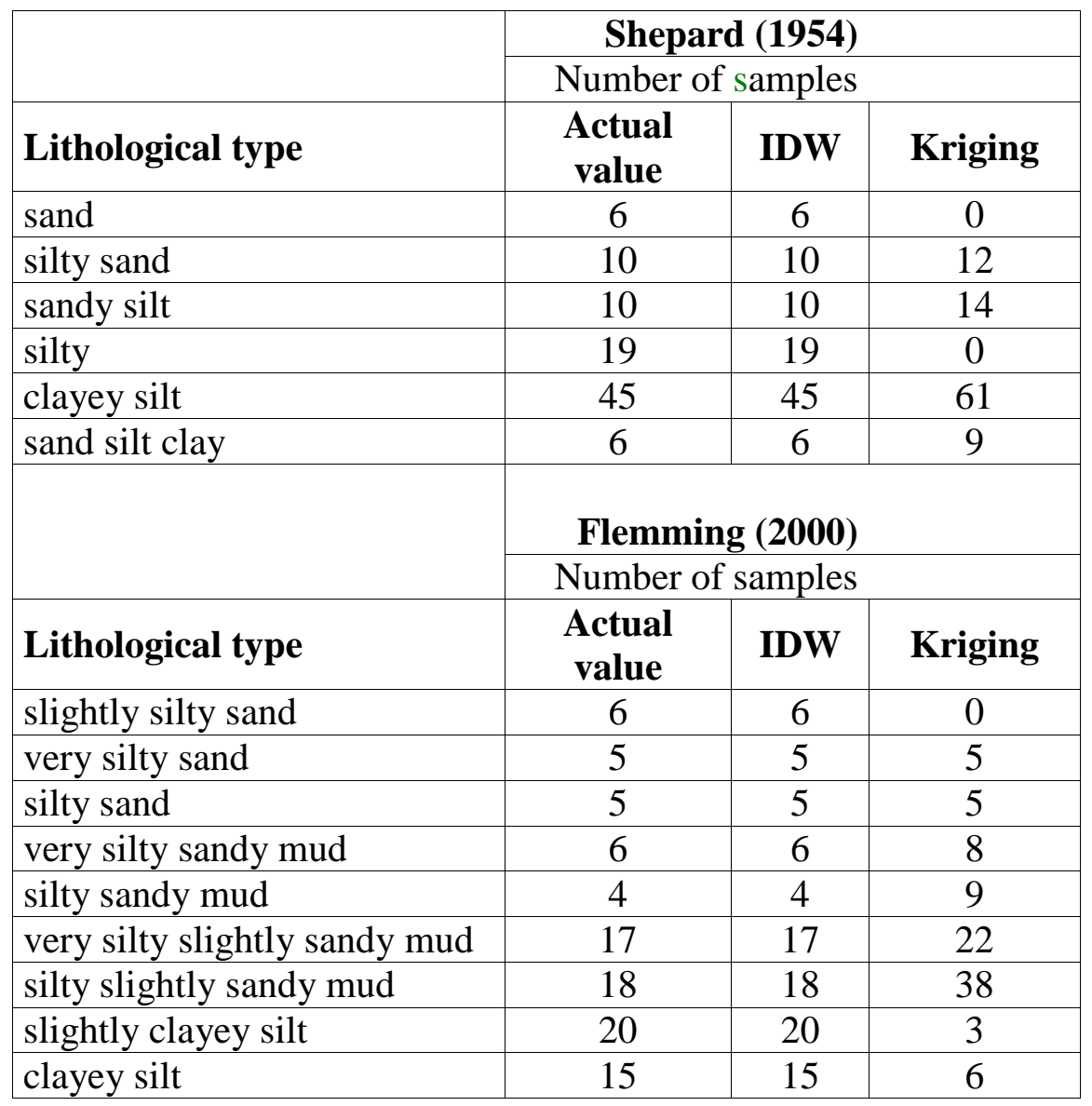




\section{FIGURE CAPTIONS}

Fig. 1. Ternary diagrams for textural classification of sediments based on sand/silt/clay ratios: Shepard's system (a) and Folk's system (b). Gravel/sand/mud ratios: (c) Folk et al.'s system. $\mathrm{G}=$ gravel; $\mathrm{S}=$ sand; $\mathrm{M}=$ mud; $\mathrm{g}=$ gravely; $\mathrm{s}=$ sandy; $\mathrm{m}=$ muddy; (g) = slightly gravely.; (d) Blair and McPherson's system plus a TD of an improved textural classification taking hydrodynamic subdivisions into account, based on sand/silt/clay ratios: (e) Flemming's system.

Fig. 2. Diagram of algebraic operations made by applying MA algorithm to three input files. Output files (lower left) show values associated with various classes identified by a triangular diagram (right).

Fig. 3. TD of surface sediments from Lagoon of Venice, based on sand/silt/clay ratios, from Shepard (1954) (a) and Flemming (2000) (b).

Fig. 4. Map produced automatically after writing algorithm in raster calculator, depicting spatial distribution of sediment textural classes in Lagoon of Venice, according to Shepard (1954).

Fig. 5. Map produced automatically after writing algorithm in raster calculator, depicting spatial distribution of sediment textural classes in Lagoon of Venice, according to Flemming (2000).

Fig. 6. TD of surface sediments from Block Island Sound, based on gravel/sand/mud ratios by Folk et al. (1970) (a) and Blair and McPherson (1999) (b).

Fig. 7. Map produced automatically after writing algorithm in raster calculator, depicting spatial distribution of sediment textural classes in Block Island Sound: system of Folk et al. (1970). 

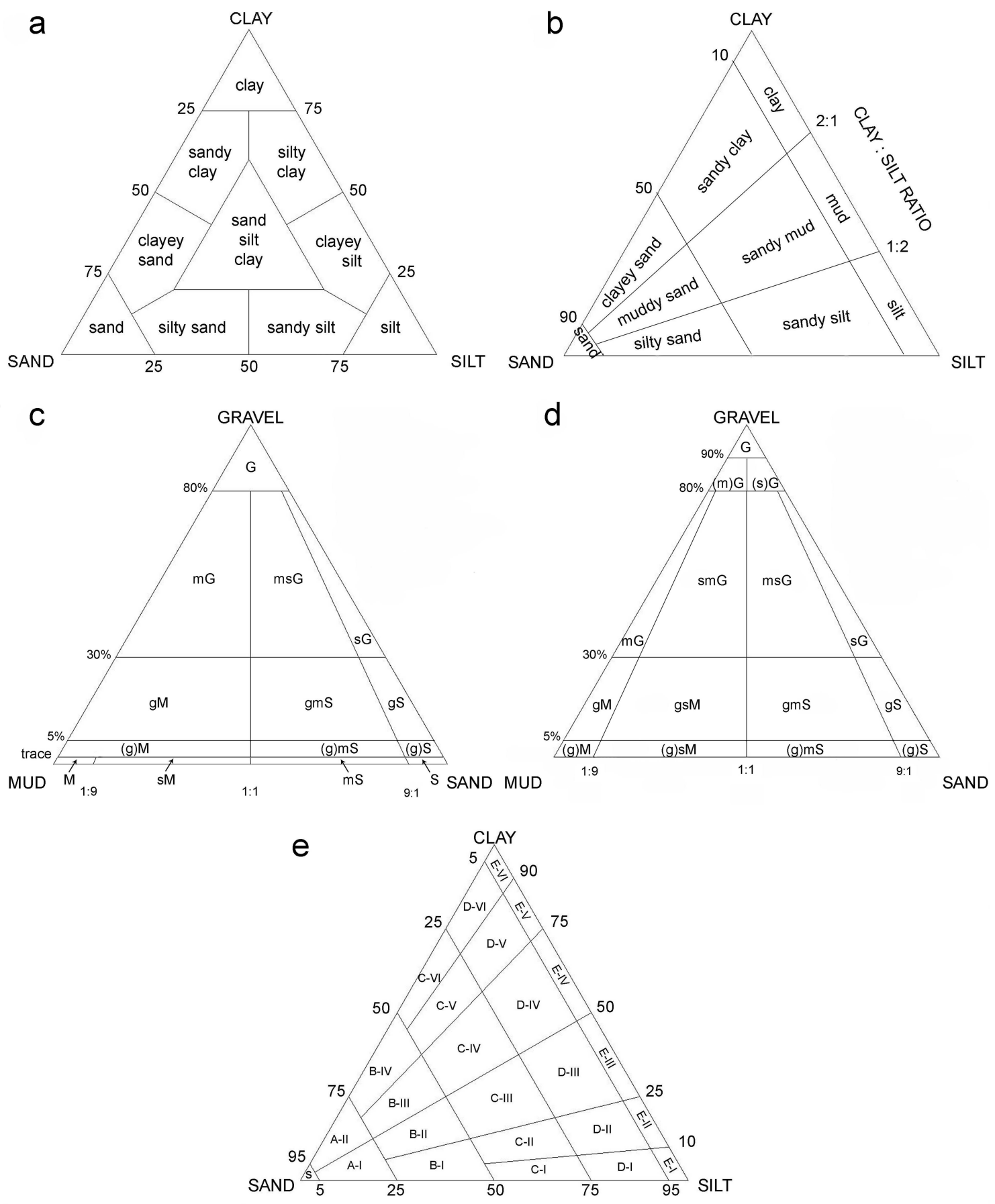

Fig. 1 


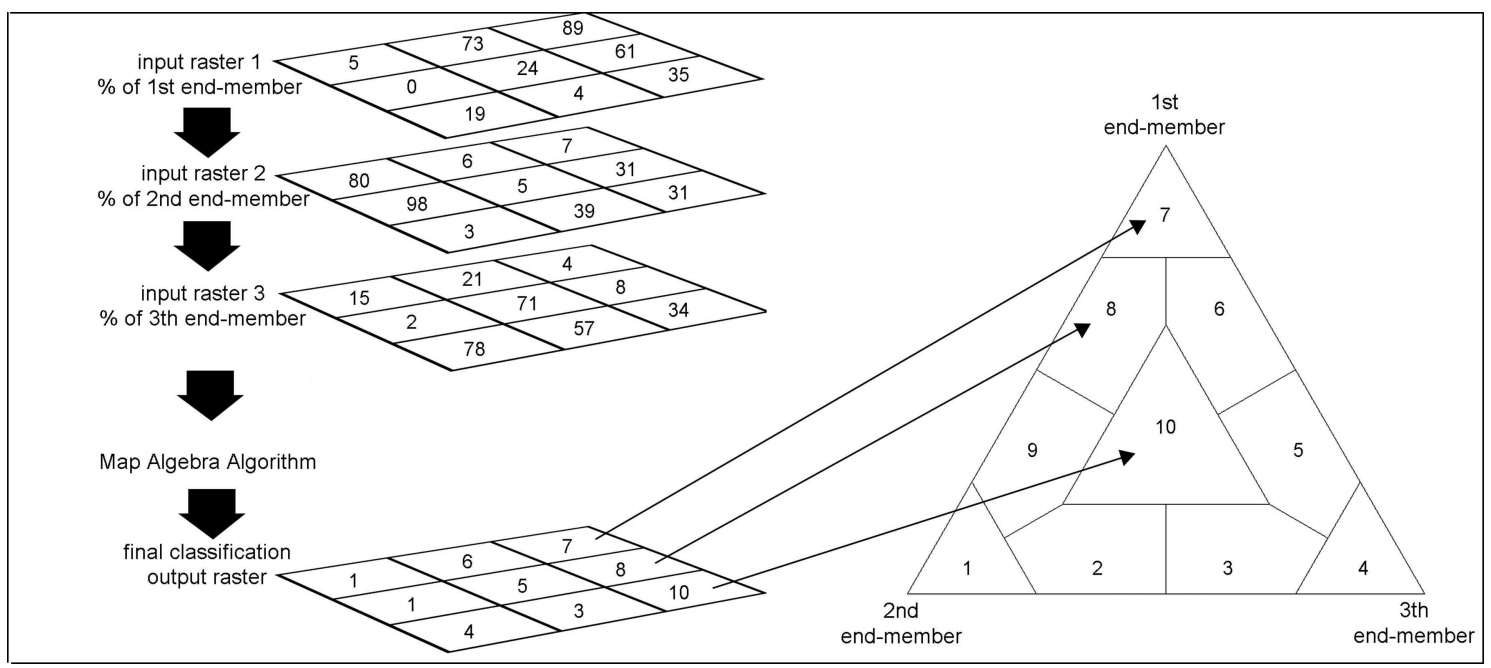

Fig. 2

a

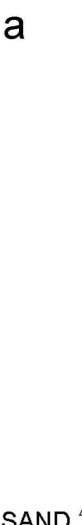

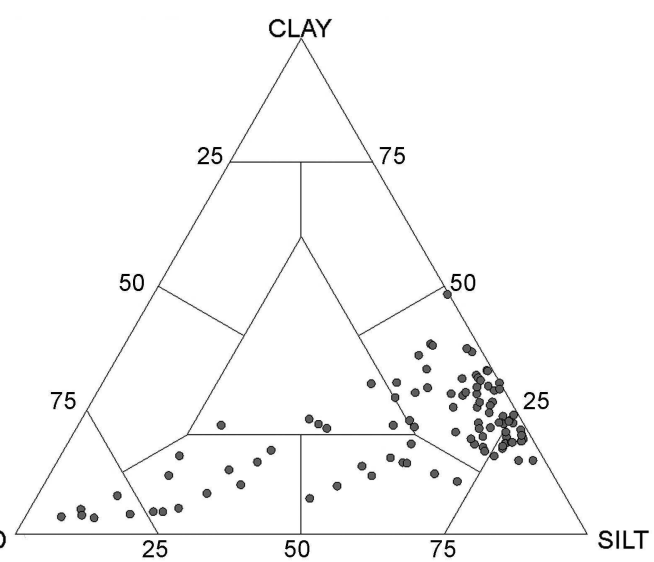

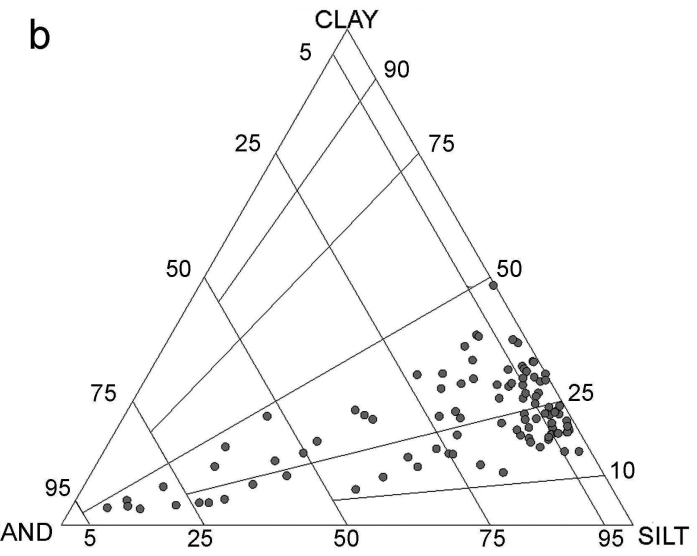

Fig. 3 


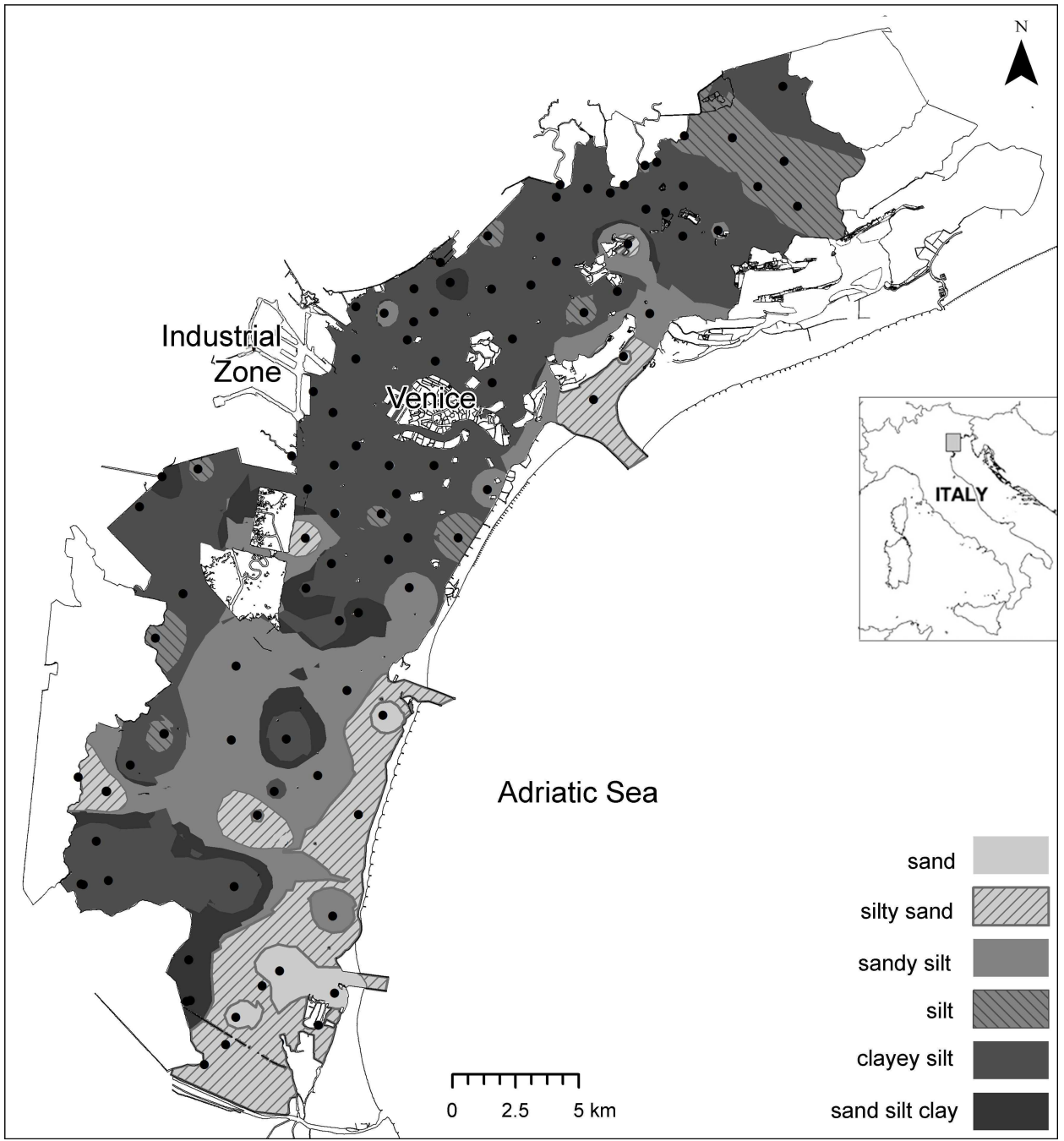

Fig. 4 


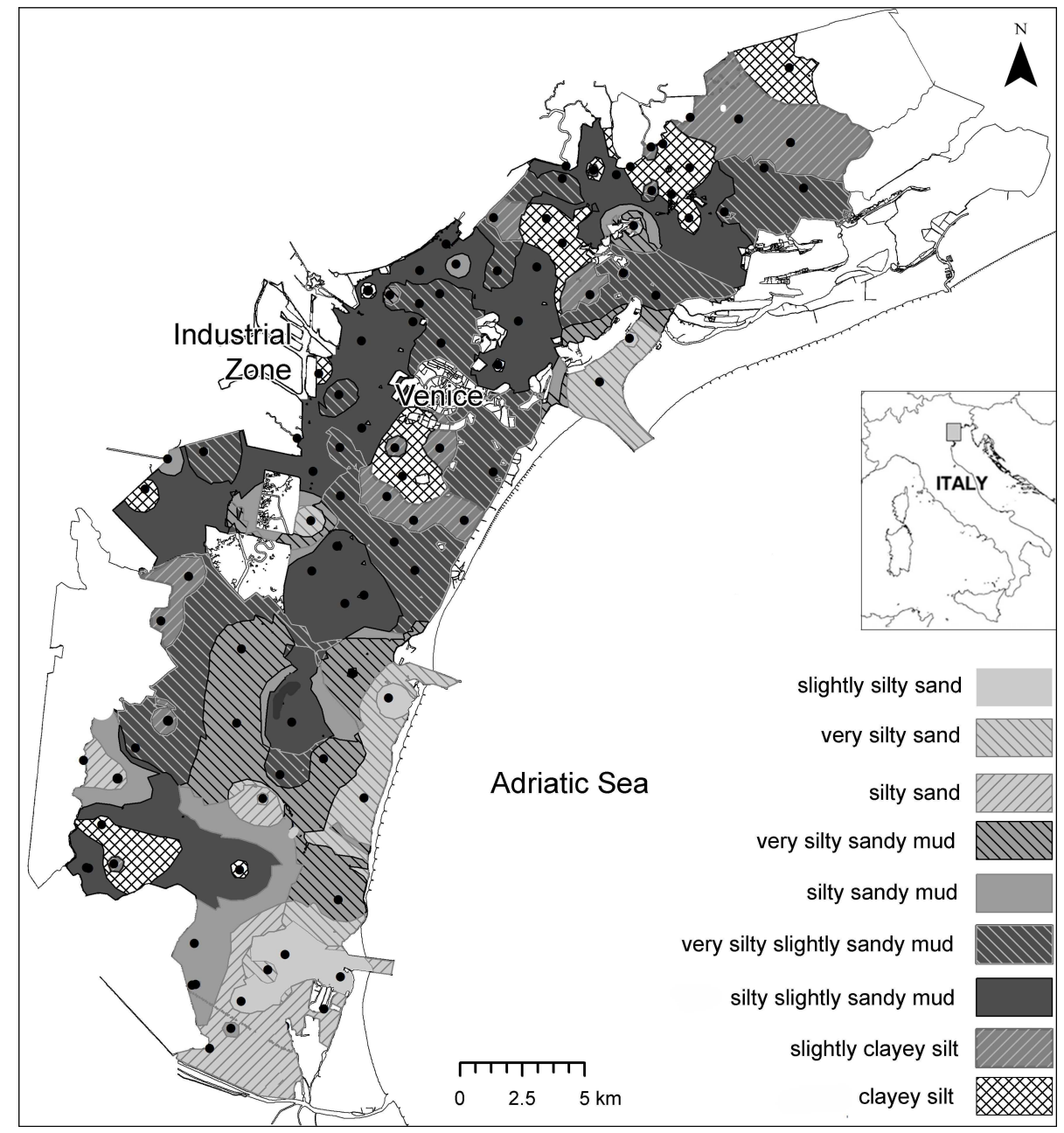

Fig. 5
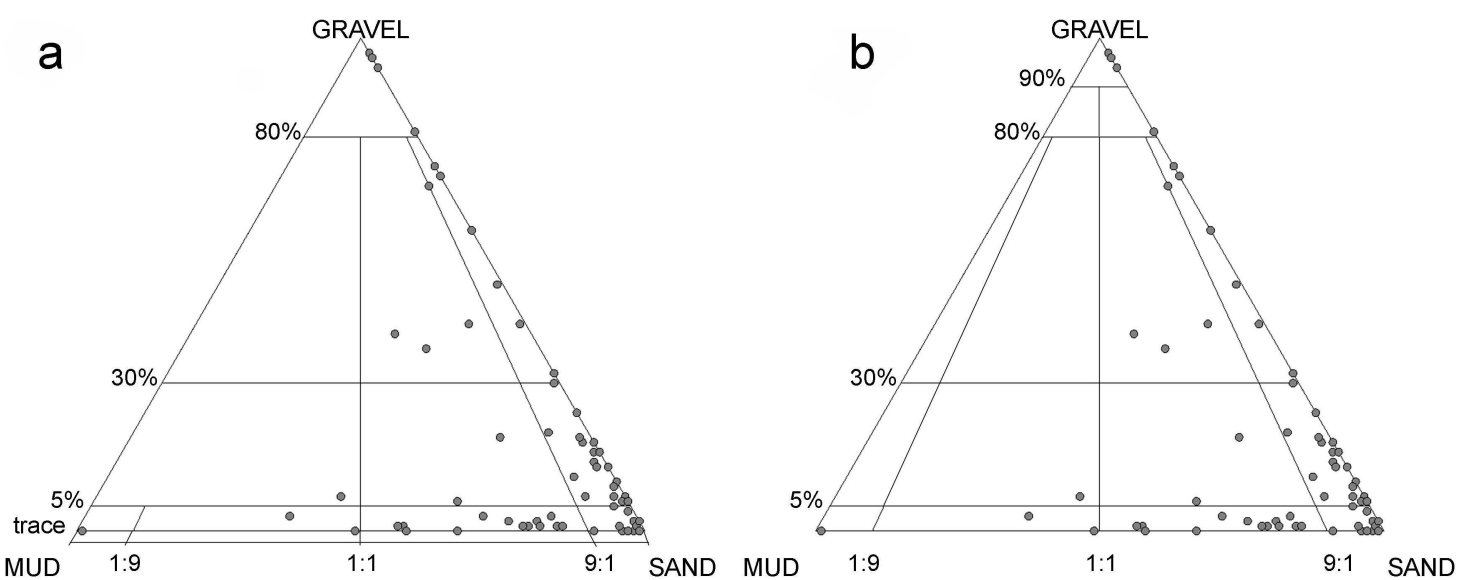

Fig. 6 


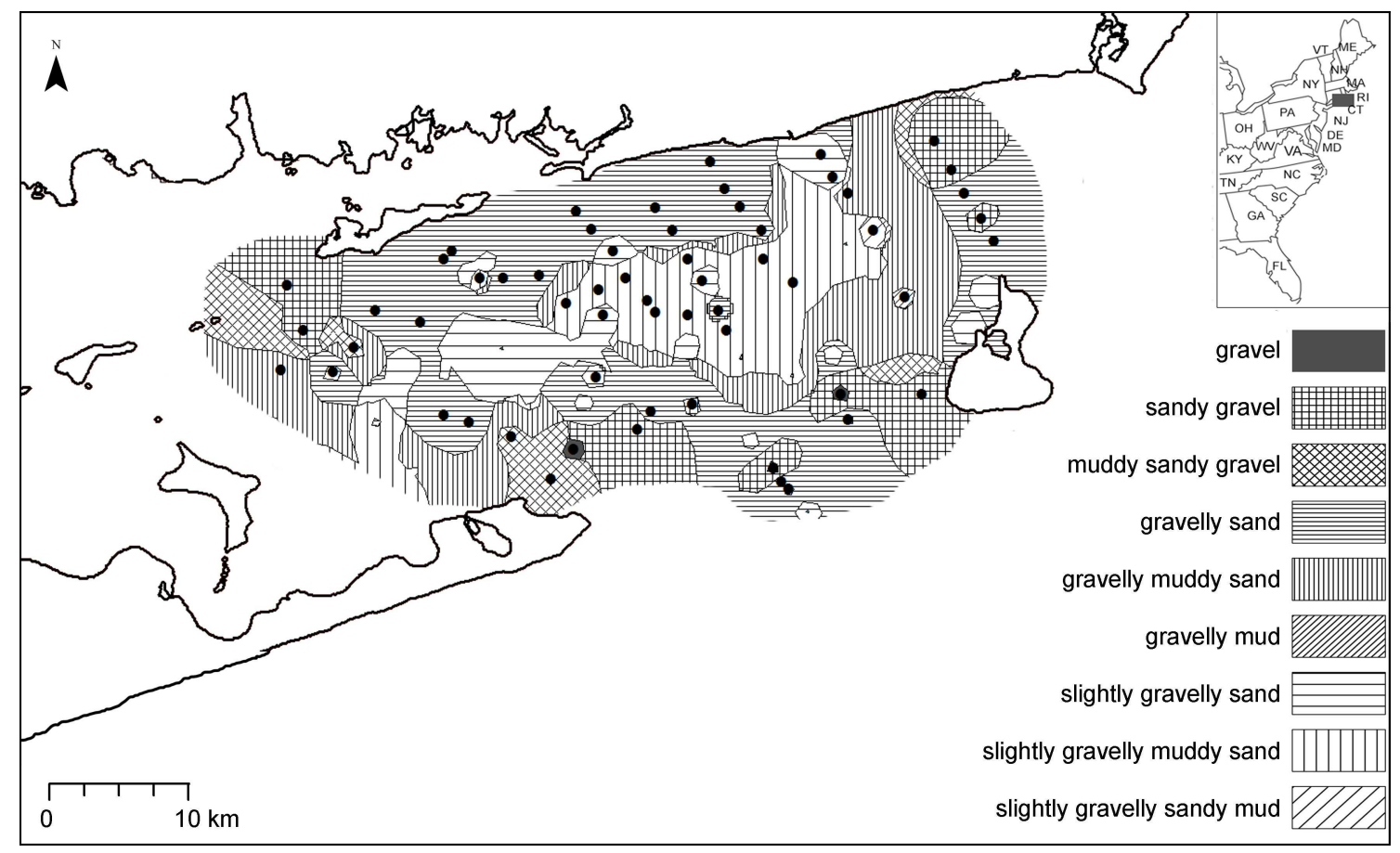

Fig. 7 